Policy Research Working Paper 4306

\title{
The Impact of Climate Change on African Agriculture
}

\author{
A Ricardian Approach
}

\author{
David Maddison \\ Marita Manley \\ Pradeep Kurukulasuriya
}

The World Bank

Development Research Group

Sustainable Rural and Urban Development Team

August 2007 
Policy Research Working Paper 4306

\section{Abstract}

This paper uses the Ricardian approach to examine how farmers in 11 countries in Africa have adapted to existing climatic conditions. It then estimates the effects of predicted changes in climate while accounting for whatever farmer adaptation might occur.

This study differs from earlier ones by using farmers' own perceptions of the value of their land. Previous research, by contrast, has relied on either observed sale prices or net revenues, sometimes aggregated over geographically large tracts of terrain. The study also makes use of high resolution data describing soil quality and runoff. Furthermore, it tackles the challenges involved in modeling the effect of climate on agriculture in a study that includes countries in the northern and

southern hemispheres, as well as the tropics.

The study confirms that African agriculture is particularly vulnerable to climate change. Even with perfect adaptation, regional climate change by 2050 is predicted to entail production losses of 19.9 percent for Burkina Faso and 30.5 percent for Niger. By contrast, countries such as Ethiopia and South Africa are hardly affected at all, suffering productivity losses of only 1.3 percent and 3 percent, respectively. The study also confirms the importance of water supplies as measured by runoff, which, being affected by both temperature and precipitation, may itself be highly sensitive to climate change.

This paper-a product of the Sustainable Rural and Urban Development Team, Development Research Group—is part of a larger effort in the group to mainstream climate change research. Policy Research Working Papers are also posted on the Web at http://econ.worldbank.org. The author may be contacted at d.maddison@ucl.ac.uk.

The Policy Research Working Paper Series disseminates the findings of work in progress to encourage the exchange of ideas about development issues. An objective of the series is to get the findings out quickly, even if the presentations are less than fully polished. The papers carry the names of the authors and should be cited accordingly. The findings, interpretations, and conclusions expressed in this paper are entirely those of the authors. They do not necessarily represent the views of the International Bank for Reconstruction and Development/World Bank and its affiliated organizations, or those of the Executive Directors of the World Bank or the governments they represent. 


\title{
THE IMPACT OF CLIMATE CHANGE ON AFRICAN AGRICULTURE: A RICARDIAN APPROACH ${ }^{1}$
}

\author{
David Maddison, Marita Manley and Pradeep Kurukulasuriya ${ }^{2}$
}

\footnotetext{
${ }^{1}$ An earlier version of this Working Paper was published as CEEPA Discussion Paper number 15.

${ }^{2}$ Respectively, the Department of Economics, University of Birmingham; the UK Department of Trade and Industry; and the UN Development Program. This paper is partly based on a dissertation of the same name written by Marita Manley and supervised by David Maddison. The empirical part of this paper uses data obtained from the project entitled Climate, water and agriculture: Impacts on and adaptations of agroecological systems in Africa and funded by the Global Environmental Facility and the World Bank. The authors would like to thank James Benhin, Ariel Dinar, Rashid Hassan, Robert Mendelsohn and Matthew Cole. Any remaining errors are the responsibility of the authors. The views expressed in this paper do not necessarily reflect those of the World bank, UK Department of Trade and Industry or the UN Development Program.

This paper was funded in part by the GEF and the World Bank. It is part of a larger study on the effect of climate change on agriculture in Africa, managed by the World Bank and coordinated by the Centre for Environmental Economics and Policy in Africa (CEEPA), University of Pretoria, South Africa.
} 


\section{TABLE OF CONTENTS}

Section

Page

$1 \quad$ Introduction

4

2 Literature review 5

3 Data 8

4 Econometric analysis $\quad 10$

5 Discussion 12

6 Conclusions 13

$\begin{array}{ll}\text { References } & 15\end{array}$ 


\section{Introduction}

There is mounting political concern about the potential impacts of future climate change. In January 2005 the EU carbon emissions trading scheme became operational and in February the Kyoto Protocol entered into force. Climate change, along with the plight of Africa, was at the top of the political agenda at the G8 summit held in Gleneagles, Scotland, in July.

Although predicting how much global warming will ultimately occur is difficult, the latest Intergovernmental Panel on Climate Change (IPCC) report suggests that the increase in global mean temperatures over the next century could be between 1.4 and $5.8^{\circ} \mathrm{C} .{ }^{3}$ Patterns of precipitation will also change, affecting the hydrological cycle. Sea levels will rise by $9 \mathrm{~cm}$ to $88 \mathrm{~cm}$, mainly through the thermal expansion of the ocean. Although the precise extent of these changes and their consequences is subject to considerable scientific uncertainty, there is one issue on which there is broad agreement (e.g. Watson et al. 1997): developing countries are especially vulnerable to climate change because agricultural productivity depends on the climate. And in developing countries agriculture employs most of the workforce and is responsible for around a quarter of GDP (World Bank 2004).

Houghton (2004) identifies three main ways in which climate change will affect the agricultural sector. First, changes in temperature and precipitation lead to changes in soil moisture. Irrigation can help reduce the sensitivity of agricultural performance to climatic variables but only if water supplies are available. The availability of such water is of course also likely to be heavily affected by climate change. ${ }^{4}$ Second, temperature has a direct effect on crop yields. Different crops have different optimal growing conditions and high temperatures can damage those already close to their maximum toleration limits under current conditions. Third, experiments have shown that elevated concentrations of carbon dioxide may promote the growth of certain crops. ${ }^{5}$

Early work on quantifying the economic impact of climate change on agriculture relied mainly on laboratory experiments which studied the effect of temperature change on crop yields. The results obtained from these experiments were then used to predict how yields might change in the field under different climate change scenarios. These exercises implicitly assumed that farmers would continue growing the same crops regardless of the climatic conditions. Subsequent work has adopted a more sophisticated linear programming approach whereby land is allocated to particular crops by profit maximizing farmers, subject to agroclimatic suitability constraints. Such models enable researchers to predict the effect of movements in agro-climatic zones on world prices, patterns of trade and production, and consumer and producer surpluses. But despite their complexity these models are nevertheless incapable of incorporating into the analysis all possible farmer adaptation strategies to changing climate. ${ }^{6}$ For a critical overview of these methodologies and the bibliographic details of key studies, see Mendelsohn \& Dinar (1999) and Kurukulasuriya \& Rosenthal (2003).

\footnotetext{
${ }^{3}$ Predictions of climate change depend on population growth assumptions, assumptions about economic growth, improvements in energy efficiency, etc. The figures quoted are global averages.

${ }^{4}$ Runoff is the amount of water which runs into rivers and streams following evaporation and transpiration by plants. It is a significant part of what remains available for human use, including irrigation (Houghton 2004).

${ }^{5}$ One could argue that changes in the geographical range of pests and diseases caused by climate change might also affect agricultural productivity.

${ }^{6}$ Other forms of adaptation include for example changes in planting dates and changes in the method of cultivation.
} 
Prevailing environmental conditions are some of the many factors that a farmer will take into account when choosing which crops to grow and which livestock to rear. Mendelsohn et al. (1994) argue that cross-sectional evidence might be used to predict how farmers would adapt to a change in environmental conditions. By regressing measures of agricultural outcomes (as revealed by land values or net revenues) on various climate and other variables, they estimated the importance of climate in determining agricultural productivity. Using the Ricardian approach, Mendelsohn et al. predicted much lower damages (and in some scenarios net benefits) to US agriculture as a result of climate change than had previously been forecast.

This paper examines the impact of climate change on African agriculture using the same cross-sectional approach to examine how farmers in 11 countries have adapted to existing climatic conditions. ${ }^{7}$ It then estimates the effects of predicted changes in climate while accounting for whatever farmer adaptation might occur. Apart from the geographical domain of its application this study differs from earlier ones by using farmers' own perceptions of the value of their land. Previous research has by contrast relied on either observed sale prices or net revenues aggregated over geographically large tracts of terrain. ${ }^{8}$ The study makes use of high resolution data describing soil quality and runoff. It also confronts the challenges involved in modeling the effect of climate on agriculture in a study that includes countries in the northern and southern hemispheres as well as the tropics.

To anticipate the results, it appears that both temperature and precipitation have a pronounced nonlinear effect on agricultural productivity. Higher temperatures are increasingly detrimental to agricultural activities, whereas more precipitation is beneficial. Runoff is also an important determinant of agricultural productivity. Combining the regression results with scenarios describing the direction and extent of climate change in Africa indicates that sizeable reductions in agricultural productivity are possible in Sub-Saharan Africa, even with cost effective adaptation. Elsewhere the impacts are more modest.

The remainder of the paper is structured as follows. Section 2 comprises a critical review of existing Ricardian analyses and an overview of the theoretical framework underpinning the approach. Section 3 describes the data available for the exercise. Section 4 reports on the results of the regression analysis linking perceived farm values with the structural and environmental attributes of the farm. Section 5 considers the plausibility of the findings and combines the regression results with country specific predictions of climate change for each of the eleven countries to obtain damage cost estimates. The final section concludes.

\section{Literature review}

Economic theory predicts that where a fixed factor of production prevents entry into an industry the factor in question will command an equilibrium rental price reflecting its productivity. If we calculate the annual net revenue a farmer generates this is the maximum amount he would be willing to pay to rent the land for a year. And when the net revenues from farming exceed the annual rental cost of land the rental rate will be bid up until excess profits are eliminated. Where land is differentiated by quality a farmer's willingness to pay

\footnotetext{
7 The countries are Burkina Faso, Cameroon, Egypt, Ethiopia, Ghana, Kenya, Niger, Senegal, South Africa, Zambia and Zimbabwe.

${ }^{8}$ There has been a parallel attempt by Kurukulasuriya and Mendelsohn (2006) to analyze the relationship between net revenues and climate variables using data from the same project.
} 
for a particular parcel of land will depend on the productive advantages of that land. In equilibrium more fertile land attracts a higher rental value equal to the increase in net revenues. Otherwise a farmer could increase profits by using more or less of such land, thereby altering its rental value.

The productive value of particular characteristics of land such as soil quality may therefore be derived from their observed importance in determining rental values or, equivalently, net revenues. The productive value of land characteristics may also be derived from the sale value of land, in which case the implicit prices of characteristics reflect their contribution to productivity in perpetuity - an observation credited to David Ricardo and developed by, among others, Palmquist (1989). Several authors have already used the Ricardian technique to estimate the implicit value of a variety of farmland characteristics, including topsoil depth and drainage. Others have used the technique to determine the implicit value of climate.

In Mendelsohn et al. (1994) US farmland prices and net revenues were regressed on climate, soil and other variables. Much of the data used related to countywide averages, and spatial statistical techniques were used to construct countywide climatic variables from weather station data. The quadratic climate terms were significant, indicating a nonlinear relationship between farm value and climate.

Kumar and Parikh (1998) analyzed the climate sensitivity of Indian agriculture using the Ricardian approach. District level estimates of annual net revenues were regressed on climate and other socio-economic variables. Difficulties were encountered in estimating input and output prices where farms were subsistence farms and a major weakness of the study is that it captures the effect of climate only on the marketed farm sector.

Sanghi et al. (1998) conducted a Ricardian study for Brazil using district averages for net revenues and land values. They determined that the impact of climate change on agricultural productivity is negative, with the most pronounced impacts being felt in the central and western regions.

Maddison (2000) presents a Ricardian study for England and Wales. The study is unusual in that it is apparently the only one to have used actual sale price at the level of the individual farm to determine the value of climate. The results point to the importance to agriculture of frost days in winter. Maddison also found that the price per hectare of land depends strongly on the size of the farm.

Using census tract data, Reinsborough (2003) examined the extent to which climate explains variation in farm values and farm net revenues for Canada. The results are of particular interest because Canadian agriculture arguably stands to benefit from global warming. Reinsborough finds that climate variables are statistically significant along with latitude and population density, but that the potentially beneficial impacts of climate change cannot be ascertained with any degree of precision.

Precipitation and temperature alone do not necessarily provide a good indication of water available for agricultural production as water supplies often come from elsewhere. Mendelsohn and Dinar (2003) consider the impact of water availability on agricultural outcomes across the US, and whether adding variables which capture the availability of ground water and surface water to the standard Ricardian model changes the climate sensitivity of agriculture. Their results suggest that the ability to irrigate land can provide a valuable buffer against adverse climatic conditions. 
Kurukulasuriya and Ajwad (2004) apply the Ricardian approach to farm level data from Sri Lanka. This additional level of detail allows the authors to control for a host of individual household and farmer characteristics such as the farmer's human and physical capital. Increases in precipitation have a positive and significant impact on net revenues, whereas temperature has a strong negative impact. Other important variables include the level of education of the head of the household and land tenure status.

Mendelsohn et al. (2004a) address the problem of weather stations often being distant from one another and concentrated mainly in urban areas, especially in developing countries. Measures of climate in between stations as required by Ricardian analyses are often inferred using spatial statistical techniques to interpolate the data. Satellite measures, by contrast, directly observe surface temperature, although they do have trouble measuring some relevant phenomenon such as precipitation. These authors found that satellite data often outperformed weather station data in terms of their ability to explain variation in farm value.

Mendelsohn et al. (2004b) examine the role of climate averages and climate variance in determining farm values. When used together, climate averages explain the bulk of variation in agricultural performance, while variance improves the explanatory power of the regressions only slightly.

On the whole, the available studies confirm the existence of a nonlinear relationship between climate variables and agricultural performance and highlight the importance of using seasonal rather than annual averages for climate variables. The availability of water supplies also appears to be a critical determinant of agricultural performance. The Ricardian approach applied to the issue of climate change nevertheless suffers from a number of limitations both in methodology and in the manner in which it has hitherto been implemented.

The validity of the welfare measures requires unchanged prices (Cline 1996). But climate change will change the global supply of agricultural produce, meaning that prices cannot help but be affected. The Ricardian technique further assumes that a farmer will, when confronted with a change in climate, immediately behave in ways similar to a farmer long accustomed to farming in such conditions. If the Ricardian approach predicts significant losses of productivity even with full and immediate adaptation then the reality will be worse. ${ }^{9}$ Fixed capital may become maladapted because of climate change (Quiggin \& Horowitz 1999).

The Ricardian technique assumes that trade in agricultural produce is sufficient to equalize the returns on differentiated factors of production in all locations. ${ }^{10}$ But impediments to the movement of goods might prevent prices for land of identical quality being equalized, particularly for land in different countries. Pooling information on land values from two or more countries might result in attempting to fit a single regression to what are essentially separate markets.

In the developing country context, data on agricultural land prices are seldom available and studies tend to use net revenues instead. But using net revenues assumes that the year studied is representative of the long run profitability of agriculture. If the survey year is atypical it might distort the results. Calculating net revenues also presents problems: valuing household labor inputs and the produce consumed by subsistence farms can be very difficult.

\footnotetext{
${ }^{9}$ Transitional costs are the difference between the maximum value of net revenues per acre following perfect adaptation and the net revenues actually realized by the farmer given his lack of knowledge with respect to the new best crops to grow and how to grow them.

${ }^{10}$ This is the factor price equalization theorem.
} 
Those studies employing farm value data typically rely on geographically aggregated sale price data. The use of such data, however, implies a loss of control since one is aggregating over potentially diverse farming enterprises. Indeed, there is an important difference between farm values which might reflect structural attributes such as farm buildings, and bare land values. Furthermore, even when individual farm sale price data is available one needs to account for the fact that in any given year only a very small fraction of farmland is likely to be put on the market. Whatever sales take place might be of farms which are unrepresentative, thereby giving rise to sample selection problems (Koundouri \& Pashardes 2003).

In this paper we use farm level data on farmer-perceived rather than actual sale value. Any remaining sample selection issues are explicitly addressed. The relative advantages and disadvantages of this choice are discussed below. We also pool data from different countries but include country dummies in an attempt to control for market segmentation.

\section{Data}

This paper uses a large dataset containing detailed information on farming activities in 11 African countries. ${ }^{11}$ Almost 10,000 farms were surveyed during 2003 and survey districts were deliberately chosen to ensure that the sample was representative of farms in different agro-climatic areas across Africa. The questionnaire included questions on household characteristics, employment of household members and the quantity of labor used in agricultural production. Detailed information was sought with respect to the type of crops grown, the amount of land used and other crop farming related costs such as seeds, fertilizer and pesticides, light, heavy and animal machinery, and farming related buildings. The survey also requested information on the type of livestock, poultry and other animals farmed. Each farm surveyed was assigned a unique identifying code enabling it to be matched with spatially referenced data on climate, runoff and land quality.

Two main sources of climate data were used. Satellite data was taken from the US Department of Defense (Basist et al. 2001). Satellites are equipped with sensors that can detect both surface temperature and wetness. The African Rainfall Temperature Evaluation System (ARTES) data was created by the National Oceanic and Atmospheric Association's Climate Prediction Centre (World Bank 2003). The ARTES data is based on ground station measurements of precipitation and minimum and maximum temperature.

The rationale for combining these two different sources of data is as follows. First, the ARTES dataset is at the provincial level as opposed to the satellite data that is available at the district level. Second, in the case of satellite-measured wetness, this measure is actually an index which partly depends on temperature. We therefore use satellite measurements for temperature and ground station measurements for precipitation.

The climate data are in the form of three-month averages, where December, March, June and September are the middle months. A particular issue arises when one is analyzing climate data drawn from countries some of which are in the northern hemisphere, some in the

\footnotetext{
${ }^{11}$ The data are obtained from an ongoing project entitled Climate, water and agriculture: Impacts on and adaptations of agro-ecological systems in Africa and funded by the Global Environmental Facility and the World Bank.
} 
southern, and some in the tropics. It would be inappropriate to expect the response to December temperatures to be the same in the northern and southern hemispheres. Instead the analysis in this paper is based on temperatures in the warmest and coolest seasons, and precipitation in the wettest and driest seasons. Quadratic terms are included to account for any nonlinearity in the relationship between climate and agricultural performance. In the African context we expect higher temperatures to have a negative effect on farm values but increased precipitation to be beneficial.

The ability to irrigate land increases land values, but whether irrigation is possible depends partly on the availability of surface runoff. Runoff is determined by, among other things, rainfall and evaporation in neighboring areas. Runoff data were provided by the University of Colorado and the International Water Management Institute as part of a broader study. Runoff is expected to have a positive impact on agricultural performance as a result of the increased availability of water for agricultural use, but may also have a negative impact if extreme rainfall causes flooding. Runoff is also represented by the maximum and minimum three-month averages and their squares.

Not all of the farms surveyed provided information on the distance to their nearest market for the purchase of their inputs or the sale of their outputs. Rather than discard observations with missing values distances were inferred using the average distance to market of other farms located in the same district. Note that distances are measured in terms of kilometers and do not make any allowance for the presence or absence of all-weather roads. Distance to market is expected to have a negative impact on land value. Farms located further from relevant markets are likely to have higher transportation costs, leading to lower profitability.

Country dummies are included to capture all the factors that cause land value to differ between countries and that are not otherwise explicitly controlled for in the regression. This could include the quality of institutions and infrastructure, impediments to trade or preferential trade links, and technology. Note that the technology currently employed by the farmer to cultivate his land does not explain differences in perceived sale value, but rather differences in the technological ability of potential buyers.

Soil data were obtained from the Food and Agriculture Organization (FAO 1996). These data contain information about the fraction of land in a particular area falling into one of 55 different categories. These categories contain information not only about soil type but also about soil texture (coarse, medium or fine) and the slope of the land (undulating, hilly or steep). This classification has been developed by soil scientists and is intended to be meaningful for determining the potential agricultural productivity of land.

Turning to the dependent variable, this study uses farmers' own perception of the worth of their land, rather than actual sale values. More specifically, the survey asked farmers the following question: 'If this farm (including land, buildings, equipment and livestock) were for sale, what would be its approximate value?' Although early studies in the US also used such data to explore the value of non-climate attributes one may nevertheless wonder whether perceptions provide an accurate measure of market value. Some farmers were, moreover, reported to be suspicious about the interviewers' motives and may have withheld or deliberately distorted their responses. Measurement errors on the dependent variable are therefore likely. ${ }^{12}$

\footnotetext{
${ }^{12}$ Econometric problems arising from the non-random ability of farmers to offer estimates of the sale value of their land are discussed below.
} 
From an econometric point of view measurement errors on the dependent variable are not necessarily a cause for concern. The usual assumption is that the measurement error has zero mean, in which case this is added to the error term in the equation and is of no consequence for OLS (Ordinary Least Squares) estimation. More important is the relationship between the measurement error and the explanatory variables. If the measurement errors are uncorrelated with the explanatory variables, OLS still produces unbiased and consistent estimators. We have no reason to suppose that any of the explanatory variables are correlated with the measurement error in this instance. Values and prices given in local currencies were converted to US\$ using market exchange rates.

One further problem is the fact that the survey asked farmers for their valuation of their entire farm including buildings, machinery and livestock. In order to obtain the value of the bare land we are therefore compelled to control for the presence of buildings, livestock and machinery by including the number of 9 different types of farm animal and 18 different types of light and heavy machinery and animal traction. ${ }^{13}$ Unfortunately differences in the age and condition of the livestock, machines and buildings were not available. In particular, only the number of buildings was available; which does not even account for their size. Farm values per hectare are displayed in Table 1. The large difference between countries presumably reflects not only differences in the inherent value of the land but also in the level of structural attributes.

\section{Econometric analysis}

The following equation represents the basic version of the econometric model estimated:

$\mathrm{V}=\beta_{1} \mathrm{~A}+\beta_{2} \mathbf{S}+\beta_{3} \mathrm{AT}+\beta_{4} \mathrm{AR}+\beta_{5} \mathrm{ATR}+\beta_{6} \mathrm{~A} \mathbf{D}+\beta_{7} \mathrm{AC}+\beta_{8} \mathrm{~A} \mathbf{L}+\varepsilon$

where V represents farm value, A is a scalar variable representing the number of hectares, $\mathbf{S}$ is a vector of structural attributes, $\mathbf{T}$ is a vector of climate variables and their squares, $\mathbf{R}$ is a vector of runoff variables and their squares, $\mathbf{D}$ is a vector of distances to relevant markets and their squares, $\mathbf{C}$ is a vector of country dummies, $\mathbf{L}$ is a vector of soil characteristics and $\varepsilon$ is an error term. We prefer to divide the equation by the number of hectares to suppress heteroscedasticity.

Note that the above functional form is consistent with the so-called 'linearity hypothesis' (Parsons 1990). This requires that the value of a plot is proportional to plot size, that the value of any environmental amenities is proportional to plot size, and that any structural attributes such as buildings enter additively since these may be bought and sold or constructed for a price independent of plot size and environmental characteristics. It is, however, quite uncertain whether the assumptions underlying the linearity hypothesis hold in the current context and most researchers generalize the functional form in ways that do not necessarily comply with the linearity hypothesis.

\footnotetext{
${ }^{13}$ Note that we distinguish between communally owned property and that which is owned outright.
} 
Although the complete dataset comprises a survey of almost 10,000 farms from 11 African countries, at several stages in the analysis the data were truncated. Farms that failed to provide an answer to questions regarding farm value were removed, since without this data the other information provided was of no value to this study, and farms that failed to provide plot size data were also removed for the same reason. In total the dependent variable was not observed for 2066 out of 9064 farmers.

The usual approach for dealing with incidental truncation is to include an explicit selection equation for the population of interest. Sample selection is only problematic from an econometric point of view if the error term from the sample selection equation is correlated with the error term from the equation of primary interest. Heckman's method for correcting this source of bias relies on identifying a variable (or variables) that could be included as an explanatory variable in the selection equation but which does not appear as an explanatory variable in the primary equation (Heckman 1979).

Variables used to identify our model include among other things the age of the respondent in years, the education of the respondent in years, the respondent's gender, whether the respondent was married, whether the respondent worked on the farm, whether the respondent also worked off-farm, whether the respondent was head of the household, and whether the respondent owned the primary plot. In particular, it seems likely that individuals who own land would be better able to answer a question regarding the value of their farm. Almost $63 \%$ of respondents claimed to have formal property rights to their primary plot of land.

For the reasons mentioned above the dependent variable was initially taken in terms of US dollars per hectare, while the structural characteristics of the land were divided by the size of the farm. ${ }^{14}$ Attempts to perform a Box Cox transformation, however, suggested that a linear functional form was inappropriate and that, contrary to theoretical expectation, a logarithmic transformation of the dependent variable resulted in a substantial improvement in fit. The reason for this is perhaps that the values of environmental characteristics are interdependent. In what follows, therefore, the dependent variable was taken as the logarithm of perceived sale value per hectare and an additional variable was included measuring farm size.

If we examine the regression equation in Table 2 we see that the number of hectares is negatively signed and indeed statistically significant. Smaller farms are evidently perceived as being worth more on a per hectare basis. This suggests that the repackaging (i.e. the subdivision or combining) of plots is prohibitively expensive in the African context.

The number of farm buildings per hectare is positively signed and highly significant. The numbers of animals per hectare of various types are generally statistically insignificant, other than the number of steers and the number of chickens, both of which are highly statistically significant. The numbers of files, weeders, ploughs etc. and non-specified forms of animal power per hectare have a statistically significant impact on farm values. Curiously, the possession of a generator diminishes farm values. Possibly this serves as a marker for those farms not served by a reliable electricity supply. ${ }^{15}$

Turning now to the environmental attributes we see that the climate variables are highly significant. The characteristic inverted U-shape is observed for both minimum and maximum temperatures. Higher temperatures are ultimately detrimental to agricultural production and

\footnotetext{
${ }^{14}$ Note that the area of the farm excludes any communally owned grazing land used by the farmer.

${ }^{15}$ The coefficient is only significant at the $5 \%$ level.
} 
furthermore the turning points are such that most if not all countries in Africa would be harmed by higher temperatures. Note also that although the coefficients for minimum and maximum temperature are individually insignificant, when taken in conjunction with one another they are highly significant. By contrast a U-shaped relationship is observed for precipitation. Higher levels of precipitation are conducive to agricultural production.

The runoff variables are also highly significant. In particular, it appears that minimum runoff is uniformly beneficial to agricultural production over the observed range. Maximum surface runoff by contrast appears to have a curvilinear relationship with farm values. The terms interacting runoff with precipitation are both negatively signed and statistically significant, indicating that the implicit value of precipitation is lower in areas characterized by ample levels of runoff.

The variables measuring distance to the place where the farmer buys his inputs and sells his output turn out to be statistically significant. This is despite the fact that distance is measured in terms of kilometers and pays no attention to the time required for the journey, nor to the presence or absence of all-weather roads. That both sets of variables are significant highlights the fact that the markets for agricultural inputs and outputs are not always located together. Furthermore, some respondents were subsistence farmers who do not sell any of their produce.

Many of the country dummies are highly significant, indicating that the differences in prevailing technology, trade links, quality of institutions and infrastructure are considerable. Many of the variables describing the type and texture of the soil and the slope of the land are highly significant.

Turning now to the selection equation, we see that the respondent's education better enabled the respondent to volunteer a suggestion as to the likely sale value of the farm. Surprisingly perhaps, being the head of the household meant that the interviewee was significantly less likely to provide information, perhaps because of a concern about the way in which any such information might be used. Predictably, however, the chief determinant of whether the respondent was able to volunteer information or not was whether the individual questioned actually owned the primary plot of land. ${ }^{16}$ Despite its significance in the regression equation there is little evidence that proximity to the market where farmers habitually buy their inputs or sell their outputs has a significant impact on the probability of them providing an estimate of the sale value of the farm. Finally, there are marked differences in the preparedness of individuals from different countries to volunteer information on perceived land values.

A Wald test readily rejects the hypothesis that the regression equation and the selection equation are independent of one another, justifying the use of the Heckman model.

\section{Discussion}

In this section the implicit values for climate attributes contained in the regression equation are combined with future climate change scenarios for each of the 11 countries in order to predict the impact of climate change on agricultural productivity. The climate change

\footnotetext{
${ }^{16}$ In some studies of net revenues it appears that the tenure status of the farmer is an important determinant of agricultural productivity. In this study we would argue that the tenure of the farmer is irrelevant to the sale value of the farm. The characteristics of the farm matter whereas the characteristics of the farmer do not.
} 
scenario underpinning this prediction is the IPCC Special Report on Emissions Scenarios (SRES) emissions scenario A1 without stabilization. Regional climate change impacts are drawn from the UK Meteorological Office's global climate model (Schlesinger \& Malyshev 2001). The global climate sensitivity to an equilibrium doubling of $\mathrm{CO}_{2}$ is set at $2.5^{\circ} \mathrm{C}$.

The country specific changes in temperature and precipitation associated with this scenario are presented in Tables 3 and 4 respectively. Using alternative input assumptions or an alternative global climate model would naturally alter the predicted impact. The climate change scenario is evaluated at the year 2050 by which time a globally averaged temperature increase of $1.1^{\circ} \mathrm{C}$ is expected, allowing for continuing negative forcing from sulphates.

Productivity impacts associated with this particular climate change scenario are presented in Table 5. These impacts are calculated by using the estimated equation to predict the change in perceived land values under the climate change scenario and expressing it as a function of land values under current climatic conditions. Note carefully, however, that what this procedure yields is an estimate of the impact of climate change on agriculture using current rather than future technology. There are three other important caveats. First, the predictions do not account for changes in productivity due to the so-called carbon dioxide fertilization effect and, second, these estimates do not account for attendant changes in runoff even though such changes might be important. Insofar as minimum runoff contributes significantly to perceived land values it is expected that this will amplify the adverse impact of climate change on productivity. Regional predictions of changes in runoff are not available. Third, recalling the discussion in earlier sections, these productivity impacts exclude transitional costs.

There is a very clear pattern portrayed in Table 5. Those countries suffering the greatest loss in productivity, namely Burkina Faso and Niger, already have very hot climates, whereas countries with cooler climates such as Ethiopia and South Africa suffer relatively little. Thus even when the predicted changes are relatively homogeneous across countries the impacts can be very different depending on the existing climate upon which these changes are overlaid. These results suggest that climate change could have a devastating impact on agriculture in Sub-Saharan Africa but more modest impacts elsewhere. Nevertheless, it is notable that climate change has a negative impact on productivity in all 11 countries.

Despite differences in the countries under consideration, the precise climate change scenario and details regarding the implementation of the Ricardian technique, these findings resonate with those from earlier studies. Mendelsohn and Dinar (1999) summarize the results from three existing studies, suggesting a change in productivity of between $-3 \%$ and $+2 \%$ for $+2{ }^{\circ} \mathrm{C}$ warming in the US, between $-9 \%$ and $-3 \%$ for $+2{ }^{\circ} \mathrm{C}$ warming in India, and between $-5 \%$ and $11 \%$ for $+2{ }^{\circ} \mathrm{C}$ warming in Brazil.

\section{Conclusions}

The Ricardian approach attempts to quantify the economic damage to agriculture arising as a result of climate change. Its main advantage over other approaches is that it attempts to account for farmer adaptation.

Ricardian studies take a measure of agricultural performance and regress it on various structural and environmental characteristics of land in an attempt to infer the implicit value of 
each attribute. These implicit values may be used to estimate the effect of changes in temperature and precipitation on agricultural productivity. Net revenues or land values can be used as the dependent variable although this study uses farmer perceptions of the worth of their farm instead.

The Ricardian approach itself has several weaknesses which need to be acknowledged and taken into account when interpreting the results. Although it attempts to capture the effect of farmer adaptation, the approach essentially assumes that the level of technology and knowledge remains constant. A further problem is that in the developing country context farms may face financial or informational constraints which serve to delay efficient adaptation. These limitations notwithstanding, the results highlight the importance of climate in determining agricultural performance. Agriculture in Sub-Saharan Africa appears particularly vulnerable to climate change, with losses in Niger approaching 30.5\%. Elsewhere the impacts on productivity are less pronounced because the climate is less extreme. But these impacts will be partly offset by the carbon dioxide fertilization effect.

Minimum runoff has a significant effect on farmland value. Changes in temperature and precipitation could have major implications for runoff and the effects of climate change may therefore be felt most severely through impacts on water supply. Future research should concentrate on modeling changes in runoff, given its importance in determining agricultural outcomes. 


\section{REFERENCES}

Basist A et al., 2001. Using the Special Sensor Microwave Imager to monitor surface wetness. Journal of Hydrometeorology 2: 297-308.

Cline WR, 1996. The impact of global warming on agriculture: Comment. American Economic Review 86: 1309-1312.

FAO (Food and Agriculture Organization), 2003. The digital soil map of the world: Version 3.6 (January), Rome, Italy.

Heckman JJ, 1979. Sample selection bias as a specification error. Econometrica 47: 153-161.

Houghton JT et al. (eds), 2001. Climate Change 2001: The Scientific Basis. Contribution of Working Group I to the third assessment report of the Intergovernmental Panel on Climate Change. Cambridge: Cambridge University Press.

Koundouri P \& Pashardes P, 2003. Hedonic price analysis and selectivity bias. Environmental and Resource Economics 26: 45-56.

Kumar K \& Parikh J, 1998. Climate change impacts on Indian agriculture: The Ricardian approach. In Dinar A et al. (eds), 1998. Measuring the impact of climate change on Indian agriculture. World Bank Technical paper 402. Washington, DC.

Kurukulasuriya P \& Ajwad M, 2004. Estimating the impact of climate change on smallholders: A case study on the agricultural sector in Sri Lanka. In Mendelsohn R et al. (eds), Cross-Sectional Analyses of Climate Change Impacts. World Bank Policy Research Working Paper No. 3350, World Bank, Washington DC.

Kurukulasuriya P \& Rosenthal S, 2003. Climate change and agriculture: A review of impacts and adaptations. Paper No. 91 in Climate Change Series, Agriculture and Rural Development Department and Environment Department, World Bank, Washington, DC.

Maddison D, 2000. A hedonic analysis of agricultural land prices in England and Wales. European Review of Agricultural Economics 27: 519-532.

Mendelsohn R \& Dinar A, 1999. Climate change, agriculture, and developing countries: Does adaptation matter? The World Bank Research Observer 14: 277-293.

Mendelsohn R \& Dinar A, 2003. Climate, water, and agriculture. Land Economics 79(3): $328-341$.

Mendelsohn R, Basist A, Williams C, Kogan F \& Kurukulasuriya P, 2004a. Climate analysis with satellite versus weather station data. In Mendelsohn $\mathrm{R}$ et al. (eds), CrossSectional Analyses of Climate Change Impacts, World Bank Policy Research Working Paper No. 3350, World Bank, Washington DC.

Mendelsohn R, Basist A, Dinar A, Williams C \& Kurukulasuriya P, 2004b. What explains agricultural performance: Climate normals or climate variance? In Mendelsohn $\mathrm{R}$ et 
al. (eds), Cross-Sectional Analyses of Climate Change Impacts, World Bank Policy Research Working Paper No. 3350, World Bank, Washington DC.

Palmquist R, 1989. Land as a differentiated factor of production: A hedonic model and its implications for welfare measurement. Land Economics 65: 23-28.

Parsons G, 1990. Hedonic prices and public goods: An argument for weighting locational attributes in hedonic regressions by lot size. Journal of Urban Economics 27: 308321.

Quiggin J \& Horowitz JK, 1999. The impact of global warming on agriculture: A Ricardian analysis: Comment. American Economic Review 89(4): 1044-45.

Reinsborough M, 2003. A Ricardian model of climate change in Canada. Canadian Journal of Economics 36: 21-40.

Sanghi A, Mendelsohn R \& Dinar A, 1998. The climate sensitivity of Indian agriculture. In Dinar A et al. (eds), 1998. Measuring the impact of climate change on Indian agriculture. World Bank Technical Paper 402. World Bank, Washington, DC.

Schlesinger M \& Malyshev S, 2001. Changes in near-surface temperatures and sea level for the post-SRES $\mathrm{CO}_{2}$-stabilization scenarios. Integrated Assessment 2: 95-110.

Watson RT, Zinyoera MC \& Moss RH, 1997. The regional impacts of climate change: An assessment of vulnerability. A special report of the IPCC Working Group II. Cambridge: Cambridge University Press.

World Bank, 2003. Africa rainfall and temperature evaluation system (ARTES). World Bank, Washington DC.

World Bank, 2004. Global Economic Prospects. The World Bank: Washington DC. 
Table 1: Perceived farm value and farm size

\begin{tabular}{lcccc}
\hline Country & $\begin{array}{c}\text { Mean value } \\
(\mathbf{\$} / \mathbf{h a})\end{array}$ & $\begin{array}{c}\text { Median value } \\
\mathbf{( \$ / \mathbf { h a } )}\end{array}$ & $\begin{array}{c}\text { Mean size } \\
\mathbf{( h a )}\end{array}$ & $\begin{array}{c}\text { Median size } \\
\text { (ha) }\end{array}$ \\
\hline Burkina Faso & 1662 & 500 & 6.9 & 5.5 \\
Cameroon & 1835 & 952 & 3.0 & 2.4 \\
Egypt & 34009 & 28351 & 2.1 & 1.0 \\
Ethiopia & 972 & 455 & 125.7 & 2 \\
Ghana & 2206 & 581 & 3.7 & 2.1 \\
Kenya & 12466 & 5720 & 265.8 & 2.4 \\
Niger & 221 & 119 & 8.9 & 6.5 \\
Senegal & 8691 & 3162 & 7.1 & 6 \\
South Africa & 11646 & 1084 & 590.2 & 19 \\
Zambia & 934 & 250 & 20.1 & 1.2 \\
Zimbabwe & 8691 & 3162 & 3.6 & 2 \\
\hline
\end{tabular}

Source: See text. 
Table 2: Heckman sample selection model

Method $=$ Maximum likelihood

Dependent variable $=\log ($ Perceived sale value $/$ Area $)$

\begin{tabular}{|c|c|c|}
\hline Variable & Parameter & T-statistic \\
\hline Area (ha) & -0.00011 & -8.56 \\
\hline Buildings / Area & 0.189149 & 5.93 \\
\hline Steers / Area & 0.008287 & 6.34 \\
\hline Cows / Area & 0.007854 & 0.79 \\
\hline Bulls / Area & -0.00125 & -0.06 \\
\hline Goats / Area & -0.00076 & -0.55 \\
\hline Sheep / Area & $6.85 \mathrm{E}-05$ & 0.46 \\
\hline Pigs / Area & $6.22 \mathrm{E}-06$ & 0.06 \\
\hline Oxen / Area & -0.00365 & -0.34 \\
\hline Chickens / Area & $1.61 \mathrm{E}-05$ & 8.72 \\
\hline Other animals / Area & 0.0007 & 0.92 \\
\hline Cutlasses / Area & -0.01456 & -1.24 \\
\hline Hoes / Area & 0.012841 & 1.58 \\
\hline Files / Area & 0.101821 & 4.83 \\
\hline Axes / Area & 0.005212 & 1.42 \\
\hline Baskets / Area & 0.001374 & 1.3 \\
\hline Weeders / Area & 0.016705 & 2.33 \\
\hline Other light machinery / Area & 0.005145 & 0.95 \\
\hline Tractors / Area & 0.036165 & 0.27 \\
\hline Ploughs / Area & 0.465452 & 6.5 \\
\hline Trailers / Area & 0.452548 & 1.77 \\
\hline Threshers / Area & 0.042495 & 0.48 \\
\hline Fodder cutters / Area & 0.091438 & 0.78 \\
\hline Generators / Area & -0.07987 & -2.39 \\
\hline Sprayers / Area & 0.070716 & 1.83 \\
\hline Other heavy machinery / Area & 0.005229 & 1.28 \\
\hline Bullocks / Area & 0.063403 & 1.97 \\
\hline Mules / Area & 0.040163 & 1.06 \\
\hline Other animal power / Area & 0.144637 & 3.79 \\
\hline
\end{tabular}


Table 2 (continued):

\begin{tabular}{|c|c|c|}
\hline Variable & Parameter & T-statistic \\
\hline Minimum temperature $\left({ }^{\circ} \mathrm{C}\right)$ & 0.160874 & 3.11 \\
\hline Minimum temperature squared & -0.00545 & -3.94 \\
\hline Maximum temperature $\left({ }^{\circ} \mathrm{C}\right)$ & 0.051888 & 0.71 \\
\hline Maximum temperature squared & -0.00243 & -1.74 \\
\hline Minimum precipitation (mm) & -0.00237 & -0.59 \\
\hline Minimum precipitation squared & 0.000153 & 2.06 \\
\hline Maximum precipitation (mm) & -0.00881 & -3.39 \\
\hline Maximum precipitation squared & $6.96 \mathrm{E}-05$ & 5.14 \\
\hline Minimum runoff $\left(\mathrm{m}^{3}\right)$ & 0.035993 & 4.78 \\
\hline Minimum runoff squared & 4.47E-05 & 0.32 \\
\hline Maximum runoff $\left(\mathrm{m}^{3}\right)$ & -0.00972 & -4.17 \\
\hline Maximum runoff squared & 0.000041 & 4.49 \\
\hline Minimum precipitation $\mathrm{x}$ minimum runoff & -0.00037 & -2.61 \\
\hline Maximum precipitation $\mathrm{x}$ maximum runoff & $-6.4 \mathrm{E}-05$ & -3.74 \\
\hline Distance to selling market $(\mathrm{km})$ & 0.0057 & 1.96 \\
\hline Distance to selling market squared & $-3.4 \mathrm{E}-05$ & -2.79 \\
\hline Distance to buying market $(\mathrm{km})$ & -0.01507 & -3.81 \\
\hline Distance to buying market squared & 0.000123 & 4.38 \\
\hline Burkina Faso & -0.76157 & -3.5 \\
\hline Cameroon & -1.13984 & -6.55 \\
\hline Egypt & 1.909942 & 8.67 \\
\hline Ethiopia & -1.65035 & -11.36 \\
\hline Ghana & -0.67796 & -4.11 \\
\hline Kenya & 0.172575 & 1.07 \\
\hline Niger & -1.45412 & -7.44 \\
\hline Senegal & 0.475615 & 2.77 \\
\hline South Africa & -0.4499 & -1.01 \\
\hline Zambia & -1.83234 & -8.64 \\
\hline
\end{tabular}


Table 2 (continued):

\begin{tabular}{|c|c|c|}
\hline Variable & Parameter & T-statistic \\
\hline Chromic cambisols medium steep & 2.380105 & 5.25 \\
\hline Eutric cambisols medium fine & 56.49106 & 1.37 \\
\hline Calcic cambisols medium undulating & 1.100862 & 4.78 \\
\hline Calcic cambisols coarse undulating & 1.554085 & 1.79 \\
\hline Vertic cambisols fine & 2.639124 & 6.87 \\
\hline Vertic cambisols medium undulating & 15.56165 & 5.48 \\
\hline Orthic ferralsols fine undulating & -0.09185 & -0.36 \\
\hline Rhodic ferralsols fine undulating & 0.986719 & 2.53 \\
\hline Rhodic ferralsols fine hilly or steep & -24.8004 & -1.3 \\
\hline Eutric gleysols coarse undulating & -1.36048 & -2.16 \\
\hline Eutric gleysols medium or fine undulating & -0.60898 & -0.87 \\
\hline Calcaric lithosols medium or fine steep & 86.21134 & 1.65 \\
\hline Lithosols & 0.467518 & 1.36 \\
\hline Luvic lithosols & 0.514331 & 0.87 \\
\hline Luvic lithosols fine & 3.178128 & 8.58 \\
\hline Rhodic lithosols hilly & 1.740482 & 0.72 \\
\hline Lithosols steep & 13.28705 & 5.66 \\
\hline Calcaric fluvisols coarse undulating or hilly & -0.5617 & -0.99 \\
\hline Calcaric fluvisols medium or fine undulating & 0.948228 & 8.72 \\
\hline Chromic luvisols medium undulating or hilly & -1.03044 & -1.59 \\
\hline Chromic luvisols fine undulating & -1.5119 & -3.63 \\
\hline Chromic luvisols medium or fine undulating & -0.99198 & -2.89 \\
\hline Chromic luvisols medium steep & -3.92269 & -2.02 \\
\hline Chromic luvisols coarse or medium hilly or steep & 0.406211 & 0.63 \\
\hline Ferric luvisols undulating & 0.47433 & 2.75 \\
\hline Ferric luvisols coarse undulating & 0.340456 & 2.66 \\
\hline Ferric luvisols coarse medium undulating & 0.048496 & 0.22 \\
\hline Ferric luvisols & 0.998038 & 3.16 \\
\hline
\end{tabular}


Table 2 (continued):

\begin{tabular}{|c|c|c|}
\hline Variable & Parameter & T-statistic \\
\hline Gleyic luvisols & -1.22691 & -2.82 \\
\hline Gleyic luvisols coarse undulating & -1.25566 & -5.87 \\
\hline Gleyic luvisols medium undulating & 0.147908 & 0.55 \\
\hline Gleyic luvisols fine undulating & 1.867769 & 0.66 \\
\hline Calcic luvisols medium undulating or hilly & 0.370506 & 0.19 \\
\hline Orthic luvisols medium hilly & 2.362602 & 0.57 \\
\hline Plinthic luvisols coarse undulating & -0.95683 & -2.63 \\
\hline Plinthic luvisols & 0.480093 & 1.23 \\
\hline Dystric nitosols medium undulating & 0.493785 & 1.54 \\
\hline Dystric nitosols & 1.976769 & 4.65 \\
\hline Albic arenosols coarse undulating & -0.80103 & -0.93 \\
\hline Cambic arenosols & -1.18276 & -2.54 \\
\hline Cambic arenosols type $1 \mathrm{a}$ & 0.495068 & 2.67 \\
\hline Luvic arenosols & 1.383526 & 2.33 \\
\hline Luvic arenosols coarse undulating & 0.375151 & 2.58 \\
\hline Eutric gleysols & 0.336819 & 1.81 \\
\hline Eutric gleysols coarse undulating & -0.42341 & -1.67 \\
\hline Chromic vertisols & 0.538492 & 2.17 \\
\hline Chromic vertisols fine undulating & -3.29596 & -2.78 \\
\hline Eutric planosols medium or fine hilly & -37.9086 & -1.8 \\
\hline Solodic planosols medium undulating or hilly & 1.928601 & 0.7 \\
\hline Solodic planosols & -1.67347 & -2.34 \\
\hline Solodic planosols coarse undulating & 1.784952 & 3.84 \\
\hline Calcic xerosols medium undulating or hilly & -0.3953 & -0.54 \\
\hline Calcic yermosols medium undulating or hilly & 0.355882 & 1.7 \\
\hline Gleyic solonchaks coarse undulating & -0.87366 & -1.63 \\
\hline Constant & 6.994132 & 8.6 \\
\hline
\end{tabular}


Table 2 (continued):

\begin{tabular}{|c|c|c|}
\hline $\begin{array}{l}\text { Variable } \\
\text { Selection equation }\end{array}$ & Parameter & T-statistic \\
\hline Area (ha) & 4.54E-06 & 0.43 \\
\hline Age (years) & -0.00128 & -1.02 \\
\hline Education (years) & 0.013473 & 3.19 \\
\hline Male & 0.079183 & 1.1 \\
\hline Married & 0.016853 & 0.27 \\
\hline Farm worker & 0.192298 & 2.59 \\
\hline Also works off farm & -0.02964 & -0.85 \\
\hline Head of household & -0.16697 & -4.52 \\
\hline Owns primary plot & 0.272851 & 7.28 \\
\hline Distance to selling market $(\mathrm{km})$ & 0.002549 & 2.38 \\
\hline Distance to buying market $(\mathrm{km})$ & 0.000427 & 0.26 \\
\hline Burkina Faso & -0.03263 & -0.29 \\
\hline Cameroon & 0.628297 & 5.64 \\
\hline Egypt & 1.024767 & 7.91 \\
\hline Ethiopia & -0.22334 & -1.98 \\
\hline Ghana & 0.43134 & 3.84 \\
\hline Kenya & 0.927892 & 8.22 \\
\hline Niger & 0.499671 & 4.18 \\
\hline Senegal & 0.518239 & 4.45 \\
\hline South Africa & 0.184535 & 1.39 \\
\hline Zambia & -0.27404 & -2.55 \\
\hline Constant & 0.182519 & 2.05 \\
\hline Number of observations & \multicolumn{2}{|c|}{9063} \\
\hline Number of censored observations & \multicolumn{2}{|c|}{2066} \\
\hline Wald test (zero slopes) & \multicolumn{2}{|c|}{$\chi^{2}(112)=25439$} \\
\hline Wald test (independence of equations) & \multicolumn{2}{|c|}{$\chi^{2}(1)=9.68$} \\
\hline
\end{tabular}

Note: The t-statistics are heteroscedastic-consistent. 
Table 3: Change in temperature by $2050\left({ }^{\circ} \mathrm{C}\right)$

\begin{tabular}{lcccc}
\hline Country & NDJ & FMA & MJJ & ASO \\
\hline Burkina Faso & +1.2 & +1.2 & +0.9 & +0.9 \\
Cameroon & +0.9 & +1.0 & +0.9 & +1.0 \\
Egypt & +1.2 & +1.4 & +1.4 & +1.4 \\
Ethiopia & +0.9 & +1.0 & +1.0 & +0.7 \\
Ghana & +1.2 & +1.2 & +0.8 & +0.9 \\
Kenya & +0.7 & +0.8 & +1.0 & +1.0 \\
Niger & +1.2 & +1.4 & +1.3 & +1.1 \\
Senegal & +1.0 & +1.0 & +1.1 & +1.0 \\
South Africa & +1.2 & +1.3 & +1.2 & +1.4 \\
Zambia & +1.2 & +0.9 & +1.0 & +1.1 \\
Zimbabwe & +1.0 & +1.0 & +1.0 & +1.3 \\
\hline
\end{tabular}

Source: See text.

Table 4: Change in precipitation by 2050 (\%)

\begin{tabular}{lcccc}
\hline Country & NDJ & FMA & MJJ & ASO \\
\hline Burkina Faso & -75 & +2 & 0 & +1 \\
Cameroon & +5 & 0 & 0 & -1 \\
Egypt & -8 & -9 & -44 & -12 \\
Ethiopia & +5 & +6 & +5 & +12 \\
Ghana & -7 & -4 & 0 & -2 \\
Kenya & +14 & +3 & 0 & +18 \\
Niger & 0 & 0 & +1 & +11 \\
Senegal & -66 & +300 & +1 & +5 \\
South Africa & -1 & +1 & +4 & 0 \\
Zambia & 0 & +6 & +33 & -25 \\
Zimbabwe & +3 & +4 & +7 & -20 \\
\hline
\end{tabular}

Source: See text. 
Table 5: The impact of climate change on farm productivity (\%)

\begin{tabular}{lc}
\hline Country & \% Change \\
\hline Burkina Faso & -19.9 \\
Cameroon & -16.8 \\
Egypt & -5.2 \\
Ethiopia & -1.3 \\
Ghana & -13.8 \\
Kenya & -9.8 \\
Niger & -30.5 \\
Senegal & -18.8 \\
South Africa & -3.0 \\
Zambia & -6.0 \\
Zimbabwe & -4.9 \\
\hline
\end{tabular}

Source: See text. 